\title{
Tool for Analyzing the Risks in Dangerous Goods Transportation
}

\author{
Nikolaos Vagiokas, Christos Zacharias \\ ENSCIENCE LTD, Nicosia, Cyprus \\ Email: vagiokas@enscience.eu
}

How to cite this paper: Vagiokas, N. and Zacharias, C. (2021) Tool for Analyzing the Risks in Dangerous Goods Transportation. Open Access Library Journal, 8: e7373. https://doi.org/10.4236/oalib.1107373

Received: March 31, 2021

Accepted: May 21, 2021

Published: May 24, 2021

Copyright $\odot 2021$ by author(s) and Open Access Library Inc.

This work is licensed under the Creative Commons Attribution International License (CC BY 4.0).

http://creativecommons.org/licenses/by/4.0/ (c) (i) Open Access

\begin{abstract}
Transportation of Dangerous goods by road may have serious consequences in case of an accident occur. The consequences of a road accident of a heavy goods vehicle carrying dangerous goods may affect not only the truck driver but also the nearby population present. Routing selection is a complicated issue influenced from a number of parameters that may vary during the day, a week or a month. The purpose of the research is to develop a preliminary tool concerning the Transportation of Dangerous Goods which will prove whether a risk analysis using real time data (traffic flows, meteorological conditions, etc.) can offer higher level of safety to the society and the personnel involved in the transportation. The final goal is to enhance safety by making the Dangerous Goods (DG) Risk transportation totally digitalized as a risk management process with real time data acquisition and real time risk assessment through an online platform linked with Global Positioning System (GPS). During the research the risk analysis conducted taking into account all critical parameters for two selected routes. All the necessary data derived from annual statistical data and "simulated" real time data. Data collected concerned all the critical parameters and constraints in order to compare the results to be comparable. Risk quantification was implemented using the DG Quantitative Risk Assessment Model (QRAM) and was illustrated in terms of $\mathrm{F} / \mathrm{N}$ curves. The results of this research were compared with the ones existed till today which are calculated based on annual statistical data for the above-mentioned factors. The results obtained were compared by means of Societal Risk expressed by Expected Value (EV) and showed that specific factors affect the final routing selection because of the calculated risk.
\end{abstract}

\section{Subject Areas}

Material Experiment 


\section{Keywords}

Road Safety, Dangerous Goods, Risk Assessment

\section{Introduction}

Dangerous goods transportation by road involves risks and has a potential to harm not only the truck's driver, but also the population being present at a certain distance along the pathway of the truck. Nowadays heavy goods vehicles carrying dangerous goods select their route based on risk analysis evaluated with average values derived from annual statistical data, indicating a possible route which certainly will not be the optimum during the entire time period of each different day of a year.

Transport of dangerous goods in urban areas has seriously safety implications and has become an increasingly important item on the political agenda. In most European inner cities, transport of dangerous goods has become a major concern, particularly in metropolitan areas where economic and industrial activities are integrated in urban life. In Europe, transport of dangerous goods is usually regulated by defining special routes and/or restricting access to certain areas by vehicles size. Dangerous goods are often restricted from using designated bridges and tunnels. In such cases, alternative routes bypass dense urban areas. Apart from routing, there is a usual phenomenon in large cities which aims to the rush hours in traffic. Vehicles carrying dangerous goods should avoid these routes either for safety reasons or for economic reasons aiming to the carrier company, in order to reduce the fuel consumption and increase the everyday efficiency of the vehicle driver. So, there is no tool to combine all these factors that will optimize the route and at the same time reduce the cost to the possible level that safety will be achieved. In addition, today the risk analysis is evaluated based on average values derived from annual data, indicating a possible route which certainly will not be the optimum during the entire time of each different day.

Transportation of Dangerous Goods differs from normal transportation within the frame of risk. Risk is the most popular item studied by majority of the authors dealing with dangerous goods transportation. For the recent studies; Toumazis and Kwon [1], studied on minimizing the risk experienced by the dangerous goods shipment transportation in any given time-dependent; Chakrabarti and Parikh [2], prepared a risk-based study of route evaluation, and Cappanera and Nonato [3], focused on how to efficiently compute the Pareto frontier given by the non-dominated solutions with respect to total risk and total cost on realistic instances taken from the literature.

In addition, routing of vehicles carrying dangerous goods has been the second main concern of the articles about dangerous goods transportation. From early 1980 s to 2014, the researchers have studied on routing the dangerous goods and they mainly focused on local-global routing, transportation mode, vehicle type, 
single-multi commodity, single-multi objective routing of dangerous goods transportation. Traditionally, main consideration for dangerous goods transportation was about cost and safety. Therefore, for routing dangerous goods vehicles while carriers are trying to decrease their transport cost, local or global authorities should care about the safety of population. For the recent studies on routing of dangerous goods Mahmoudabadi and Seyedhosseini [4], dealt with the principle of dangerous goods routing problem and fundamental concerns of chaos theory for defining dynamic variables were combined to develop a mathematical model while risk and time are prioritized by corresponding coefficients. Carriers and governments must have strategies in order to reduce transport risk. Time of the transportation is important. Government and local authorities serve as supervisor to dangerous goods carriers and, they allocate road segments or available population zones within a time period. The carriers should route and schedule their dangerous goods vehicles according to restrictions of the authorities to minimize transport risk.

All the researchers focusing on the Dangerous Goods (DG) routing till today mentioned in the above attempts have not tried to solve the problem in a local context combining all this data: 1) Minimum Length Path 2) Minimum Risk Path 3) Minimum time spent path 4) Routes that DG are forbidden 5) Meteorological aspects in order to develop a useful tool which will optimize the route, the time of the delivery, the type of vehicle, the availability of driver and customer following the regulation and safety constraints in real time while aiming to the lowest possible cost and maximum safety level.

This research aims to develop a preliminary tool concerning the transportation of Dangerous Goods taking into account all the above-mentioned factors, which will prove whether a risk analysis using real time data can offer higher level of safety to the society and the personnel involved in the transportation. This research presents a tool for risk analysis using real time data, which will specify with indisputable accuracy among others the exact periods for specified time-windows for the passage of for the passage of vehicles carrying dangerous goods. In this research, DG Tool combined all the critical factors (traffic flows, meteorological conditions, population density etc.) in order to conduct a preliminary analysis for the optimization of the transportation routes for DG vehicles in urban cities and mainly in highly crowded cities. To achieve this a risk analysis using "simulated" real time data was implemented taking into account all required input data and legislative framework [5] for the transportation of dangerous goods in a selected routing part.

The quantification of risk was achieved using the Quantitative Risk Assessment Model (QRAM). DG QRAM has been developed by World Road Association (www.piarc.org) for assessing the risks from dangerous goods transportation through open roads and road tunnels. [6] The results of this preliminary risk analysis were compared with the ones existed till today which are calculated based on annual data for the above-mentioned factors. These results act as proof 
of concept for further investigation and improvement of the DG Tool in order to make the Dangerous Goods Risk transportation totally digitalized with real time data acquisition.

\section{Risk Assessment}

Risk assessment is structured as a process resulting from the interaction between certain parameters such as, the vehicle or traveling risk source, the transportation network and the impact area. DG Tool uses "simulated" real time data concerning all the critical parameters in order to conduct a risk analysis taking into account all required input data including meteorological, traffic and other factors for the transportation of dangerous goods in the selected part of the route.

The necessary data considered in order to conduct the risk assessment for the transportation of dangerous goods and the selection of the optimum routing were derived from the traveling risk source, the transportation network and the impact area [7] (Figure 1).

The vehicle or traveling risk source was characterized by the probability $(\mathrm{P})$ of an outcome (i), such as fire or explosion, which, in case of an accident, depends on the type of dangerous good ( $\mathrm{dg}$ ) being carried. The consequences of a road accident involving dangerous goods can be different types of fires (pool fire, flash fire, jet fire), explosions (vapor cloud explosion VCE, boiling liquid expanding vapor explosion BLEVE) and release and dispersion of toxic substances (toxic gas cloud).

\subsection{Methodology}

In order to analyse the risks in dangerous goods transportation, the transportation network was considered and viewed as a graph $G=(M, A)$ formed by the node set $\mathrm{N}_{\mathrm{M}}$ and arc set $\mathrm{N}_{\mathrm{A}}$ and a certain amount of shipments of dangerous goods (dg) that are made yearly from node $\mathrm{O}$ (origin) to node $\mathrm{D}$ (destination) [7]. In our case the selected route to perform the preliminary risk assessment has

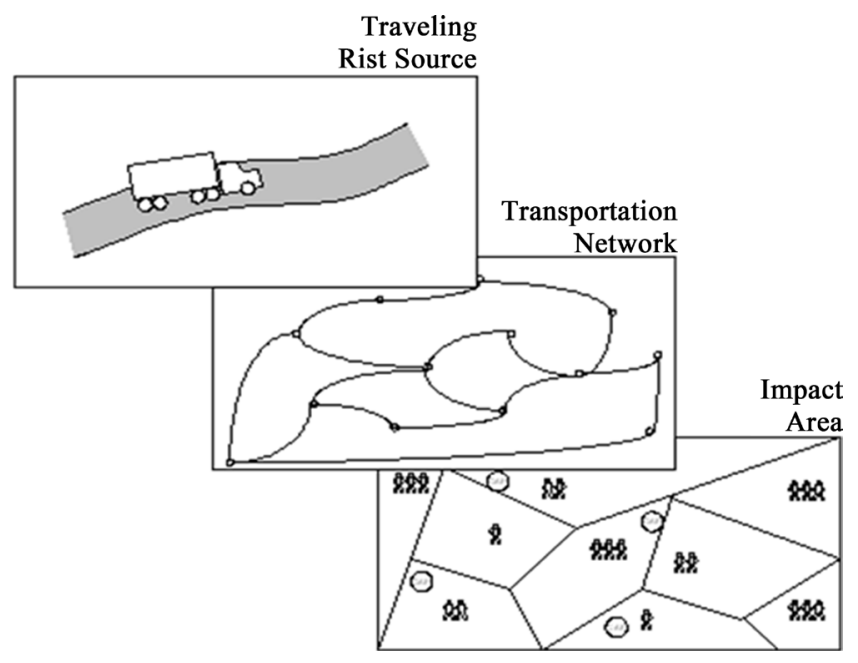

Figure 1. Risk assessment steps. 
a starting point (Origin, Long: 34.69262, Lat: 32.94529) and an ending point (Destination, Long: 34.67804, Lat: 32.79812) on the Basic route.

Two different routes were evaluated, the first one, the Basic route uses the Motorway and passes through a tunnel while the Alternative route after the starting point exits the Motorway using the National road network passing through inhabitat areas to reach, at the same point with the Basic Route, at the Motorway. The alternative route is used in order to bypass the tunnel but passes through residential and touristic areas. The transportation route was viewed as a linear risk source, since a release may occur at any point. This means that each point of the route will be considered as a point risk source. All arcs (A) were divided into a number of links $\left(\mathrm{N}_{1}\right)$, each link (l) having the same properties across its length. The impact area was characterized by certain population distribution and meteorological conditions.

The risk assessment methodology followed includes the stages of risk analysis, risk evaluation and risk reduction. The first step of the risk analysis stage was the description of the selected route, where the geometrical and the traffic characteristics along with the operating procedures and the emergency planning were described. Afterwards, in the hazard identification step all potential hazards that may result in particular risks were identified and categorized. For each potential risk, a frequency and consequence analysis was performed resulting in risk estimation. Following the risk estimation step, a risk evaluation is performed by comparing the risk estimation with the risk criteria. In case the risk criteria are satisfied, the risk level is acceptable. On the other hand, where the risk is above the acceptable level, additional measures are proposed and the procedure of risk assessment is being performed again until the risk falls in levels where acceptable criteria are met.

Risk estimation, also referred to as risk characterization, is the final step in risk assessment. Its goal is to produce measures for the risks that are being assessed. The measures are usually referred to as indices of risk. Typically, risk indices are simple numbers selected to characterize some important aspect of the risk. For the estimation of risks involved during transportation of dangerous goods, the individual and societal risk indices are used. In DG Tool project Societal Risk index will be evaluated.

Societal Risk is the relationship between frequency and the number of people suffering from a specified level of harm in a given population from the realization of specified hazards. Societal Risk is expressed in the form of cumulative F-N curves, which are plots of the cumulative frequency $(\mathrm{F}(\mathrm{n}))$ of $\mathrm{N}$ or more people receiving the specified level of harm per year, against the number of people $(\mathrm{N})$ receiving the specified level of harm. F-N curves are usually plotted on a log-log scale. In the calculation of societal risk, it is usual for the specified level of harm to be a fatality. [8] Unlike in the calculation of individual risk, the number of people exposed to the risk is taken into account in the calculation of societal risk. Once both the frequency, $f_{i}$, and the number of fatalities, $n_{i}$, has 
been calculated for each event, it is possible to estimate the societal risk [6] [7].

The results of this analysis conducted for the DG Tool project include the Societal risk index in the form of cumulative F-N curves that will be presented at the relevant Annexes. These results will be compared with the ones existed till today which are calculated based on annual data according to following the above-mentioned methodology including all the necessary factors.

\subsection{Quantitative Risk Assessment Model}

In order to conduct risk analysis, for transportation of vehicles carrying dangerous goods, is used the quantitative risk assessment model (QRAM) of the Organization for Economic Cooperation and Development (OECD) and the International Association of Road (PIARC). QRA model can quantify the hazards associated with the transport of dangerous goods through open roads and road tunnels. The selected risk assessment model (QRAM) quantifies the probability of happening a specific event and the severity of the consequences if the event occurs [6].

As consequences are considered loss of life, with distinction between road users, tunnel staff and the people who live near the tunnel, non-fatal accidents, with distinction between road users, tunnel staff and the people who live near the tunnel, buildings or structures damages of the same tunnel or other located nearby, and environmental damage.

The configuration of the regulations governing the passage of vehicles carrying dangerous goods, takes into account one or more criteria to evaluate or compare the risk. The main criteria are assessment of risk, based on one or more risk thresholds. Any kind of criteria can be used, such as the mathematic formula of "expected value", one or more threshold curves $\mathrm{F} / \mathrm{N}$, the maximum acceptable number of deaths etc. Comparison between one or more routes, for selecting the route which in terms of risk is the most advantageous, on the basis of a number of prescribed criteria. And finally, a combination of the above type of criteria.

In accordance with the guidelines of the Organization for Economic Cooperation and Development (OECD) and the PIARC, to quantify the risk of transporting dangerous goods through open roads and road tunnels are used thirteen (13) final scenarios that may occur, as consequences, on the sequence of events of a road accident [8]. In our case the $6^{\text {th }}$ scenario was excluded due to the absence of chlorine transportation [6].

The risk analysis has two stages. In the first stage, some limited data are collected. Using this data and the model QRAM, we can calculate the intrinsic risk d. As a "counter" of this risk, it has been selected the Expected Value (EV), which expresses the number of deaths due to accidents in the tunnel with dangerous goods involved, given that there are no restrictions on their transport. This value is derived as output of the analysis that uses the model QRAM. The analysis of the second stage requires the collection of much more data which will 
define the detailed characteristics of the route that includes the tunnel and the alternative route. The analysis of the second stage is divided into two steps. In the first step, we define the alternative routes (up to $i=3$ ) and compare the expected value EV1 of the route that includes the tunnel with each of the expected values EV2 (i) of the alternate routes. There are three cases:

- $(\mathrm{EV} 1 / \mathrm{EV} 2)<3$ : due to the uncertainties of the data and the model, the risk of the two routes is considered as equivalent and will have to select the route using other criteria,

- $3<(\mathrm{EV} 1 / \mathrm{EV} 2)<10$ : Sensitivity analysis is required to determine the classification in the other two cases,

- $(E V 1 / E V 2)>10$ : Route 2 is selected over Route 1 [8].

- The second step is carried out only when the expected value cannot give reliable and conclusive results. The criteria, which are usually used in the analysis of this step, are:

- Risk aversion,

- Accidents involving trucks carrying dangerous goods, with no dangerous goods involved in the accidents,

- Vulnerability of the route to accidents involving dangerous goods by economic and environmental perspective,

- Financial consequences of the decision.

\section{DG Tool Data Input}

Data collected in order to perform the risk assessment concern Census data, Meteorological data, Traffic Data, Geographical data, etc.. DG Tool considered all these factors in order to develop a useful tool capable to optimize the route following the regulations and safety constraints in real time while aiming to the lowest possible cost and maximum safety level.

For the needs of the risk assessment the Basic route is passing through the Motorway has been split at eight (8) sections due to their unique characteristics. This is also the case for the alternative route examined but split at fewer sections due to the absence of a tunnel structure. The route is separated into several sections in order different and more precise data to be attributed in each section. For the needs of this preliminary risk analysis the coordinates of each point that define one section must be converted in Lambert projection. Following Table 1 presents the coordinates of these points that define the selected routes.

For each one of the selected routes a preliminary risk analysis was conducted with analytical data sets for certain periods of time. Also, a risk analysis with annual derived data was performed in order to evaluate the results and conclude with the proposed route selection. The input data necessary to perform the risk analysis for each case are presented at the following paragraphs.

\section{Route description}

The risk due to DG transport will be evaluated between Point A and Point G 
for the Basic route and between Point A and Point $\mathrm{F}$ for the Alternative route which passes through the National Road network (Figure 2). One tunnel has been constructed at the selected part of the Basic route which is $900 \mathrm{~m}$.

The Basic route has 2 lanes in each direction for the traffic. There is either a physical separation or a Jersey barrier between the two traffic directions. The selected part of the route to be examined passes through a tunnel which is $900 \mathrm{~m}$ long while the total length of the route is $16.1 \mathrm{Km}$. There is no other tunnel for the traffic going from point A to point G. Speed limit for light vehicles is set at $100 \mathrm{~km} / \mathrm{h}$ and for heavy vehicles at $80 \mathrm{~km} / \mathrm{h}$ except from the part inside the tunnel where the speed limit decreases for all vehicles at $80 \mathrm{~km} / \mathrm{h}$ [9].

For the needs of the risk assessment certain sections between point $\mathrm{D}$ and point $\mathrm{E}$ has been calculated with a null length. These are Section 4 with East direction, Section 5 for both directions, Section 6 with West direction. The length of each section considered for the risk assessment is the following:

- Section 1:3.600 m

Table 1. Coordinates of points that define the selected routes.

\begin{tabular}{|c|c|c|c|c|c|}
\hline \multicolumn{3}{|c|}{ Alternative Route } & \multicolumn{3}{|c|}{ Basic Route } \\
\hline \multirow[t]{2}{*}{ Point } & \multicolumn{2}{|c|}{$\begin{array}{l}\text { Coordinates in WGS-84 } \\
\text { in projection Lambert }\end{array}$} & \multirow[t]{2}{*}{ Point } & \multicolumn{2}{|c|}{$\begin{array}{l}\text { Coordinates in WGS-84 } \\
\text { in projection Lambert }\end{array}$} \\
\hline & Lon $\left({ }^{\circ}\right.$ East $)$ & Lat $\left({ }^{\circ}\right.$ North) & & Lon $\left({ }^{\circ}\right.$ East $)$ & Lat $\left({ }^{\circ}\right.$ North $)$ \\
\hline A & $4,193,490$ & $8,360,975$ & A & $4,193,490$ & $8,360,975$ \\
\hline B & $4,197,143$ & $8,360,036$ & B & $4,196,447$ & $8,359,125$ \\
\hline $\mathrm{C}$ & $4,200,882$ & $8,358,165$ & $\mathrm{C}$ & $4,198,579$ & $8,358,010$ \\
\hline $\mathrm{D}$ & $4,202,950$ & $8,355,917$ & $\mathrm{D}$ & $4,201,475$ & $8,354,751$ \\
\hline $\mathrm{E}$ & $4,207,154$ & $8,352,207$ & $\mathrm{E}$ & $4,201,433$ & $8,354,008$ \\
\hline \multirow[t]{2}{*}{$\mathrm{F}$} & $4,204,753$ & $8,352,002$ & $\mathrm{~F}$ & $4,204,166$ & $8,352,332$ \\
\hline & & & G & $4,204,753$ & $8,352,002$ \\
\hline
\end{tabular}

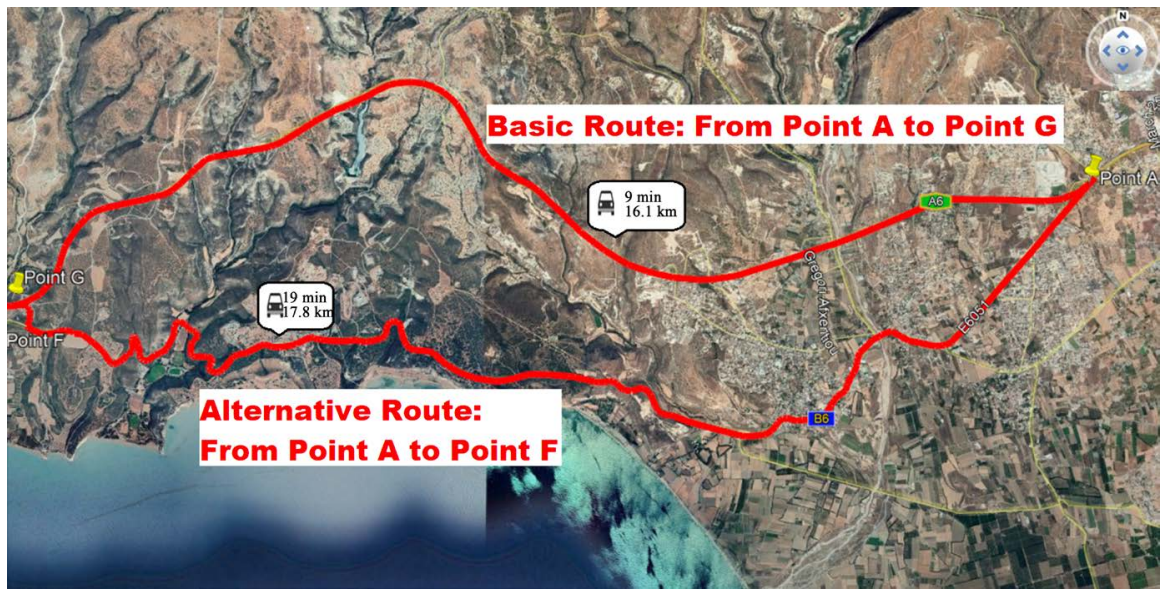

Figure 2. Selected part of the Basic and Alternative routes. Source: https://www.google.com/maps/dir/34.692536,32.9452363. 
- Section 2: $2.400 \mathrm{~m}$

- Section 3: $4.800 \mathrm{~m}$

- Section 4: $900 \mathrm{~m}$ (length only for direction to West)

- Section 5: $0 \mathrm{~m}$ (null length)

- Section 6: $900 \mathrm{~m}$ (length only for direction to East)

- Section 7:3.400 m

- Section 8: $700 \mathrm{~m}$

The Alternative route has 1 lane per direction for the traffic separated with a white line. The total length of the examined alternative route is $17.89 \mathrm{Km}$. There is no tunnel for the traffic going from point A to point F. Speed limit for all vehicles at that route is set at $50 \mathrm{~km} / \mathrm{h}$. Areas crossed by the Alternative route are of touristic interest and more densely populated areas. The length of each section is set as follows:

- Section 1: $3.700 \mathrm{~m}$

- Section 2: $4.200 \mathrm{~m}$

- Section 3: $3.060 \mathrm{~m}$

- Section 4: $5.630 \mathrm{~m}$

- Section 5: $1.300 \mathrm{~m}$

\section{Tunnel description}

Information concerning the geometrical and structural characteristics of the Tunnel has been obtained from various sources. For the needs of this preliminary risk analysis tunnel characteristics, geometrical and structural, with direction to the West were described at Section 4 while tunnel characteristics with direction to the East were described at Section 6. The tunnel isn't equipped with no emergency communication system that may be considered as mitigation measure at the risk assessment of the route [10]. The main features of the tunnel that was examined are presented at the following Table 2 [9].

\section{Period of interest}

The risk assessment conducted for the selected routes examined certain time periods in order to take into account variations observed at specific factors during

Table 2. Geometrical and structural characteristics of the tunnel.

\begin{tabular}{cc}
\hline \multicolumn{2}{c}{ Tunnel Description } \\
\hline Length of the tunnel $(\mathrm{m})$ & 900 \\
Effective width $(\mathrm{m})$ & 9.5 \\
Effective height $(\mathrm{m})$ & 7 \\
Open cross-sectional area $\left(\mathrm{m}^{2}\right)$ & 66.5 \\
Camber $(\%)$ & 0.5 \\
Open area of discrete drains or continuous slot (per Xd $\mathrm{m})\left(\mathrm{m}^{2}\right)$ & 0.22 \\
Interval between drains, or slot length used to define Ad $(\mathrm{m})$ & 50 \\
Time taken to activate emergency ventilation $(\mathrm{min})$ & 10 \\
Volume flow rate extracted from emergency ventilation regime $\left(\mathrm{m}^{3} / \mathrm{s}\right)$ & 206.15 \\
\hline
\end{tabular}


the day, the week or a month. Population distribution and total traffic show substantial differences between day and night, or weekdays and weekends [11]. Due to the fact that the alternative route passes through touristic areas, during $\mathrm{Au}$ gust, the population and the total traffic are increasing while DG-Heavy Goods Vehicles (HGV) traffic is slightly higher. These changes according to the examined time period affect the final results. So, it was decided to take into account such periodic variation and the seasonality effect and finally the risk was estimated for eight time periods plus the calculated risk estimation based to annual derived data (Period 9) (Table 3).

\section{Information on local population}

There are seven small cities or groups of villages along the selected routes or in its vicinity that the population present at these areas at the selected time periods must be calculated. Population density must be estimated in order to determine the number of persons that might be affected in case of an accident concerning a vehicle carrying dangerous goods. Population data concerning local population of the area derive from the census of population of 2011 [12].

For every section of this route the population present according to the examined time period was calculated separately. The calculations were based to the population census of 2011 [12] combined with correction factors according the type of area, time of the day, day of week and month of the year (Table 4). During the night population are at their houses while at daytime a certain amount of the population is moving at their workplaces. Touristic areas such as beaches or Hotels are crowded at August (day and night) while that population is absent at winter. The estimated population per section at the examined time periods is presented separately for the Basic and the Alternative route [11].

\section{Meteorological conditions}

The necessary meteorological data concerning the examined routes have been obtained from the Meteorological Stations located nearby and record all critical factors. Wind direction and wind speed are the more important measurements that had to be considered in order to calculate the probability to get a wind in

Table 3. Selected time periods for risk estimation.

\begin{tabular}{lc}
\hline & Time Periods for Risk Estimation \\
\hline Period 1: & August /Day/Weekdays \\
Period 2: & August/Day/Weekends \\
Period 3: & August/Night/Weekdays \\
Period 4: & August/Night/Weekends \\
Period 5: & All months except August/Day/Weekdays \\
Period 6: & All months except August/Day/Weekends \\
Period 7: & All months except August/Night/Weekdays \\
Period 8: & All months except August/Night/Weekends \\
Period 9: & Annul Data \\
\hline
\end{tabular}


Table 4. Population density per section in relation with the examined time period for each route.

\begin{tabular}{|c|c|c|c|c|c|c|c|c|c|c|}
\hline \multirow{3}{*}{$\begin{array}{l}\text { Selected } \\
\text { Route }\end{array}$} & \multirow{3}{*}{$\begin{array}{l}\text { Section } \\
\text { Number }\end{array}$} & \multicolumn{4}{|c|}{ All other Months } & \multicolumn{4}{|c|}{ August } & \multirow{3}{*}{$\begin{array}{l}\text { Annual } \\
\text { Data }\end{array}$} \\
\hline & & \multicolumn{2}{|c|}{ Weekday } & \multicolumn{2}{|c|}{ Weekend } & \multicolumn{2}{|c|}{ Weekday } & \multicolumn{2}{|c|}{ Weekend } & \\
\hline & & Day & Night & Day & Night & Day & Night & Day & Night & \\
\hline \multirow{8}{*}{ Basic Route } & Section 1 & 771 & 1.359 & 1.157 & 1.292 & 815 & 1.092 & 946 & 1.038 & 1.098 \\
\hline & Section 2 & 312 & 625 & 493 & 593 & 333 & 500 & 394 & 475 & 483 \\
\hline & Section 3 & 50 & 100 & 79 & 95 & 53 & 80 & 63 & 76 & 77 \\
\hline & Section 4 & 0 & 0 & 0 & 0 & 0 & 0 & 0 & 0 & 0 \\
\hline & Section 5 & - & - & - & - & - & - & - & - & - \\
\hline & Section 6 & 0 & 0 & 0 & 0 & 0 & 0 & 0 & 0 & 0 \\
\hline & Section 7 & 50 & 100 & 79 & 95 & 53 & 80 & 63 & 76 & 77 \\
\hline & Section 8 & 86 & 171 & 135 & 162 & 92 & 137 & 109 & 130 & 132 \\
\hline \multirow{5}{*}{$\begin{array}{c}\text { Alternative } \\
\text { Route }\end{array}$} & Section 1 & 624 & 1.200 & 968 & 1.140 & 1.252 & 1.550 & 1.369 & 1.502 & 990 \\
\hline & Section 2 & 322 & 644 & 508 & 612 & 533 & 708 & 599 & 683 & 515 \\
\hline & Section 3 & 49 & 98 & 77 & 93 & 439 & 466 & 450 & 462 & 109 \\
\hline & Section 4 & 325 & 650 & 513 & 618 & 817 & 994 & 884 & 968 & 543 \\
\hline & Section 5 & 103 & 192 & 152 & 182 & 500 & 544 & 518 & 536 & 184 \\
\hline
\end{tabular}

${ }^{\star}$ Values of the table presenting the average density of population measured in inhab $/ \mathrm{km}^{2}$.

certain direction that will affect the population in case of an accident with HGV carrying dangerous goods. The percentage of occurrence of wind has been analysed in eight compass directions and its wind speed at Beaufort scale.

Both selected routes follow similar directions and are affected from the same wind directions. The following wind rose (Figure 3 ) illustrates the meteorological data collected. These conditions are representative of meteorological conditions around the studied routes. Wind rose data depict the fact that at a percentage of more than $50 \%$ the prevailing winds come from West and North West directions.

\section{Traffic data}

In order to perform the risk analysis, traffic data have been retrieved from the relevant institution distinctly for the Basic and the Alternative route for both directions. These data were further analysed with reference recordings from Greece where each direction was simulated with these reference data. This analysis was necessary in order to calculate the hourly and monthly distribution of traffic due to lack of these data records from the relevant organisation.

Concerning the traffic data the first section of each route has increased Annual Average Daily Traffic (AADT) in relation with the other sections. Different ADDT leads to different total traffic and HGV ratio per direction and examined section. Data calculated concerning the Total traffic and HGV ratio are presented at the following Table 5 for each examined period [13]. 
Total Time ratios: 1.001
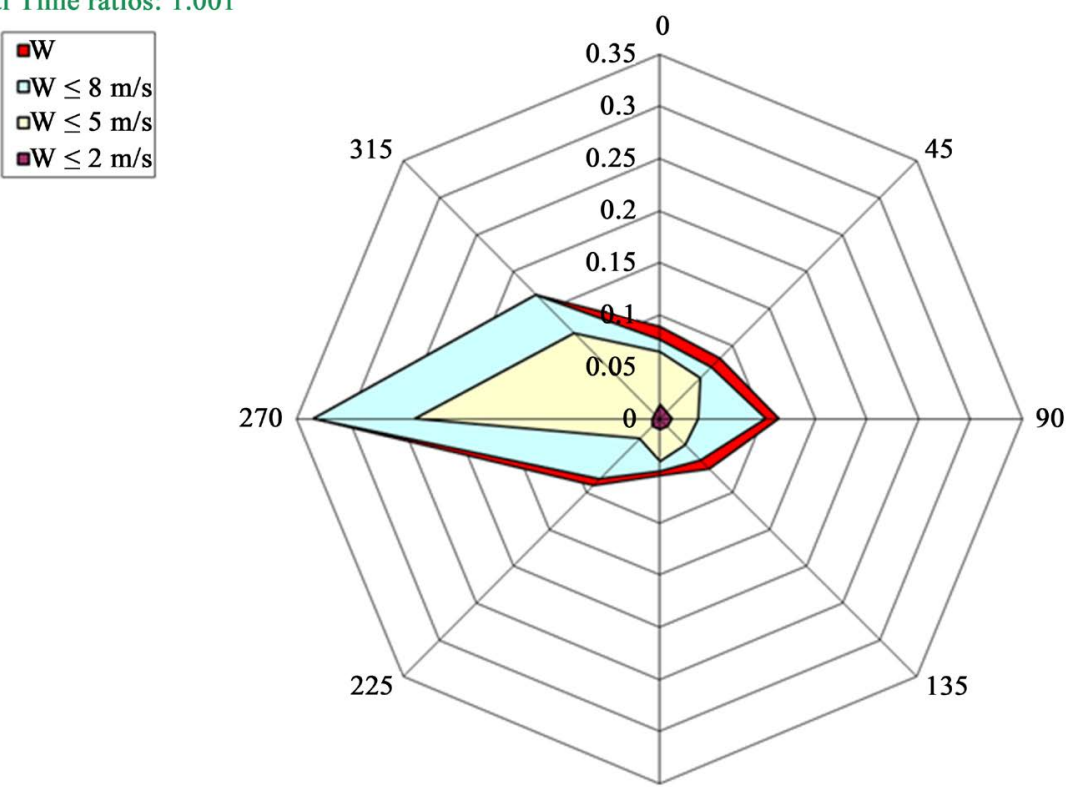

180

Figure 3. Wind Rose illustrating the prevailing winds direction.

Table 5. Total traffic and HGV ratio per direction and examined section.

\begin{tabular}{lcccc}
\hline \multirow{2}{*}{ Time Periods } & \multicolumn{4}{c}{ Traffic Data (Total traffic \& HGV Ratio) } \\
\cline { 2 - 5 } & \multicolumn{2}{c}{ Section 1 } & \multicolumn{2}{c}{ Other Sections } \\
\cline { 2 - 5 } & West Direction & East Direction & West Direction & East Direction \\
\hline Period 1 & $1.233(9.07 \%)$ & $1.254(6.13 \%)$ & $709(7.25 \%)$ & $741(6.66 \%)$ \\
Period 2 & $1.198(8.95 \%)$ & $1.223(5.97 \%)$ & $698(7.21 \%)$ & $749(6.49 \%)$ \\
Period 3 & $495(15.51 \%)$ & $412(10.18 \%)$ & $285(12.41 \%)$ & $243(11.06 \%)$ \\
Period 4 & $501(15.29 \%)$ & $402(9.97 \%)$ & $291(11.77 \%)$ & $238(10.84 \%)$ \\
Period 5 & $788(9.37 \%)$ & $825(6.04 \%)$ & $453(7.5 \%)$ & $487(6.56 \%)$ \\
Period 6 & $799(9.07 \%)$ & $819(5.88 \%)$ & $464(7.01 \%)$ & $493(6.32 \%)$ \\
Period 7 & $418(12.63 \%)$ & $359(8.87 \%)$ & $240(10.11 \%)$ & $212(9.64 \%)$ \\
Period 8 & $421(12.39 \%)$ & $351(8.16 \%)$ & $238(10.02 \%)$ & $219(9.49 \%)$ \\
Period 9 & $630(10.5 \%)$ & $618(6.9 \%)$ & $362(8.4 \%)$ & $365(7.5 \%)$ \\
\hline
\end{tabular}

In order to allocate traffic data to the hour distribution and calculate the total traffic according to the selected time periods a 24-hour day had to be divided in day and night hours. For the examined periods concerning August (Periods 1, 2, 3 and 4), day hours are from 06:00 AM till 20:00 PM while for the examined periods concerning all months except August (Periods 5, 6, 7 and 8), day hours are from 06:00 AM till 18:00 PM. [11] Busses and coaches ratio was set as a constant value $(2 \%)$ of the total traffic calculated.

\section{DG traffic}


Table 6. DG traffic per direction.

\begin{tabular}{cll}
\hline Time Periods & West Direction & East Direction \\
\hline Period 1 & 4.58 (veh/hour) & $3.15($ veh/hour) \\
Period 2 & $4.63($ veh/hour) & $3.62($ veh/hour) \\
Period 3 & $3.15($ veh/hour) & $1.72($ veh/hour) \\
Period 4 & $3.02($ veh/hour) & $1.83($ veh/hour) \\
Period 5 & $3.03($ veh/hour) & $2.04($ veh/hour) \\
Period 6 & $2.92($ veh/hour) & $1.99($ veh/hour) \\
Period 7 & $2.16($ veh/hour) & $1.31($ veh/hour) \\
Period 8 & $2.24($ veh/hour) & $1.46($ veh/hour) \\
Period 9 & $2.71($ veh/hour) & $1.75($ veh/hour) \\
\hline
\end{tabular}

Records for the hourly percentage of DG-HGV moving at the selected routes weren't available so these data were estimated according to reference recordings from Greece where each direction was simulated with these reference data. This analysis was necessary in order to conclude to the hourly and monthly distribution of DG-HGV traffic (veh/hour) due to lack of these data records from the relevant organisation. According to reference data the percentage of DG-HGV is $4.1 \%$ of the HGV moving at a certain road network. So, for the examined route and the selected periods DG Traffic was calculated as it is presented at the following Table 6. DG composition data weren't available so the France default DG composition available in QRAM was used [6].

\section{Traffic accident data}

In order to perform the risk analysis, accident data have been collected. Traffic accident frequencies are estimated, for a given length of the road, on the basis of the traffic rates and accident data registered at Eurostat. The year 2016 was taken as a reference year where the total annual number for fatalities due to road accidents was forty-six (46). If HGVs have been involved in many accidents, statistics may be derived from the observations directly for them, but in our case, accidents frequency rates are estimated for all vehicles and correction factors are applied for HGVs [13].

Accident rate response to the question: "what is the chance for a vehicle going $1 \mathrm{~km}$ to be involved in a traffic accident". The calculated accidents rates differ for each examined period and selected route. The traffic accident data calculated for this preliminary risk analysis for each examined period, selected route and traffic direction are presented at the following Table 7.

Accident rates may show substantial increase due to the seasonality when vehicles are passing through a touristic area where the total traffic of vehicles is changing between winter and summer time.

\section{Risk Estimation}

Data described at the previous chapter have been collected in order to conduct 
Table 7. Yearly accident rate for HGVs going $1 \mathrm{~km}$ involved in an accident per time period and traffic direction.

\begin{tabular}{ccccc}
\hline \multirow{2}{*}{ Time Periods s } & \multicolumn{2}{c}{ Basic Route } & \multicolumn{2}{c}{ Alternative Route } \\
\cline { 2 - 5 } & West Direction & East Direction & West Direction & East Direction \\
\hline Period 1 & $5.42 \mathrm{E}-07$ & $5.23 \mathrm{E}-07$ & $2.91 \mathrm{E}-06$ & $2.81 \mathrm{E}-06$ \\
Period 2 & $1.00 \mathrm{E}-06$ & $9.67 \mathrm{E}-07$ & $5.38 \mathrm{E}-06$ & $5.19 \mathrm{E}-06$ \\
Period 3 & $1.11 \mathrm{E}-06$ & $1.31 \mathrm{E}-06$ & $5.94 \mathrm{E}-06$ & $7.02 \mathrm{E}-06$ \\
Period 4 & $2.05 \mathrm{E}-06$ & $2.42 \mathrm{E}-06$ & $1.10 \mathrm{E}-05$ & $1.30 \mathrm{E}-05$ \\
Period 5 & $6.73 \mathrm{E}-07$ & $6.31 \mathrm{E}-07$ & $6.02 \mathrm{E}-07$ & $5.65 \mathrm{E}-07$ \\
Period 6 & $1.08 \mathrm{E}-06$ & $1.01 \mathrm{E}-06$ & $9.64 \mathrm{E}-07$ & $9.04 \mathrm{E}-07$ \\
Period 7 & $1.07 \mathrm{E}-06$ & $1.22 \mathrm{E}-06$ & $9.54 \mathrm{E}-07$ & $1.09 \mathrm{E}-06$ \\
Period 8 & $1.71 \mathrm{E}-06$ & $1.95 \mathrm{E}-06$ & $1.53 \mathrm{E}-06$ & $1.74 \mathrm{E}-06$ \\
Period 9 & $1.01 \mathrm{E}-06$ & $1.08 \mathrm{E}-06$ & $1.27 \mathrm{E}-06$ & $1.36 \mathrm{E}-06$ \\
\hline
\end{tabular}

risk analysis, for transportation of vehicles carrying dangerous goods through the selected routes.

Risk estimation resulted from QRAM software is expressed in terms of Expected Value and is calculated for the examined scenarios (Scenarios 1, 2, 3, 4, 5, $7,8,9,10,11,12$ and 13) and selected time periods for the route including the tunnel and for the alternative route. [6] The Expected value (EV) is a global indicator of societal risk and represents the annual expected fatalities from the consequences of accidents due to the involvement of the carried dangerous goods [8].

A year was split into specific time periods in order to take into account variations observed at specific factors during a day, a week or a month. Risk analysis was conducted for each of these time periods with different input data per case. Population distribution and total traffic show substantial differences between day and night, or weekdays and weekends [11]. Due to that fact the calculated Expected Values presented at the following tables resulted with different outcomes for each case.

\section{Expected value for the basic route}

The preliminary risk assessment for the Basic route conducted using the quantitative risk assessment model of the Organization for Economic Cooperation and Development (OECD) and the International Association of Road (PIARC). QRA modelling software has the capability to quantify the hazards associated with the transport of dangerous goods through open roads and road tunnels. The results of the Risk Analysis have been obtained in the form of cumulative F-N curves illustrating the calculated Expected Value per Scenario Examined (Figure 4).

There are eight (8) Scenarios Examined matching with the selected time periods. The selected time periods are presented at Table 3 of the previous chapter. All the necessary data described in detail at the previous chapter were evaluated 


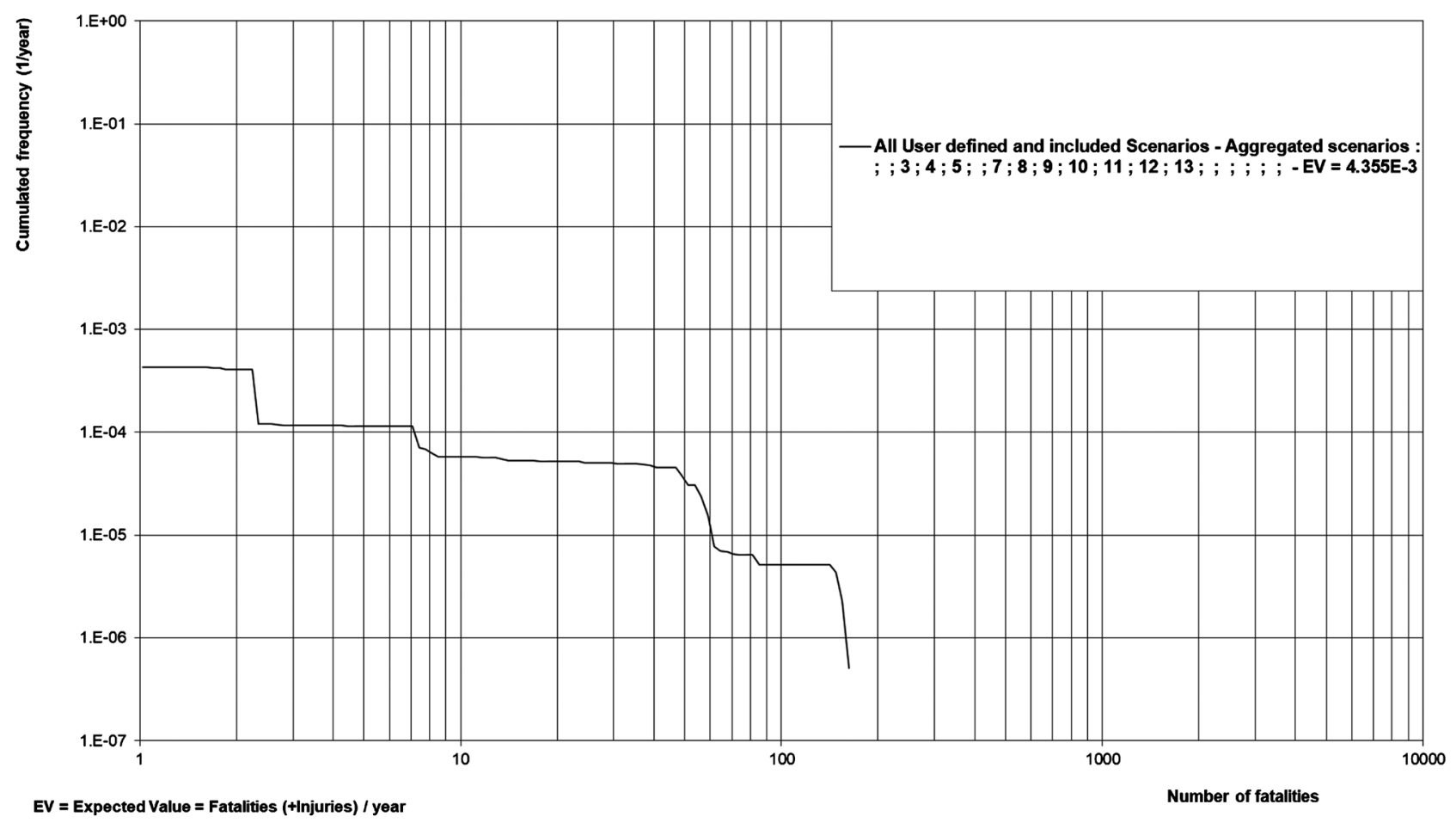

Figure 4. Societal Risk when DG-HGV passing through A6 Motorway-F/N Curve-Time period August/Day/Weekdays.

and finally inserted at the QRAM in order to calculate the cumulative F-N curves. The required input data for risk assessment entered at the software at a specific formulation in order the calculation and the results to be valid and accurate. QRAM input data concerned Route Description, Tunnel Description, Period of interest, Information on Local Population, Meteorological conditions, Traffic data, percentage of DG-HGV Traffic, Traffic accident. These data were collected and split according to the time periods selected to examine per scenario.

The quantification of the risk from vehicles carrying dangerous goods, was estimated from the risk analysis for the selected route and periods. Using these data and the model QRAM, we calculated the Expected Value (EV), which expresses the number of deaths due to accidents with dangerous goods involved, given that there are no restrictions on their transport. These values derived as output of the analysis that uses the model QRAM (Table 8).

Also, the Expected Value was calculated for the most important hazards that might occur during the transportation of dangerous goods. The following table summarizes the calculated Expected Values per time period in case vehicles are passing through the Basic route.

The resulted values presented in Table 8 calculate the annual expected fatalities from the consequences of an accident due to accidents with the involvement of heavy goods vehicle carrying dangerous goods. It is observed that Scenarios examined Period 2 and Period 4 present the higher values. These periods stand for the weekends of August during daytime and night. Interpretating the values derived only for the basic route of period 2 and period 4 the weekends of August 
Table 8. Expected value per time period when vehicles passing through the basic route.

\begin{tabular}{cc}
\hline Time Period & Calculated Expected Value \\
\hline Period 1 & $4.355 \mathrm{E}-03$ \\
Period 2 & $8.051 \mathrm{E}-03$ \\
Period 3 & $3.182 \mathrm{E}-03$ \\
Period 4 & $5.875 \mathrm{E}-03$ \\
Period 5 & $2.713 \mathrm{E}-03$ \\
Period 6 & $3.935 \mathrm{E}-03$ \\
Period 7 & $2.232 \mathrm{E}-03$ \\
Period 8 & $3.560 \mathrm{E}-03$ \\
\hline
\end{tabular}

pose higher risks for the public and the personnel involved in the transportation, therefore, the optimum routing for the transportation of dangerous goods should be allowed only from the alternative route.

Expected value for the alternative route

As it was the case with the Basic route the same procedure was followed in order to assess the risk when vehicles carrying dangerous goods pass through the Alternative route.

The preliminary risk assessment for the Alternative route conducted using the quantitative risk assessment model of the Organization for Economic Cooperation and Development (OECD) and the International Association of Road (PIARC). QRA modelling software has the capability to quantify the hazards associated with the transport of dangerous goods through open roads and road tunnels. The results of the Risk Analysis have been obtained in the form of cumulative F-N curves illustrating the calculated Expected Value per Scenario Examined (Figure 5).

There are eight (8) Scenarios Examined matching with the selected time periods. All the necessary data described in detail at the previous chapter were evaluated and finally inserted at the QRAM in order to calculate the cumulative F-N curves. The required input data for risk assessment entered at the software at a specific formulation in order the calculation and the results to be valid and accurate. QRAM input data concerned Route Description, Tunnel Description, Period of interest, Information on Local Population, Meteorological conditions, Traffic data, percentage of DG-HGV Traffic, Traffic accident. These data were collected and split according to the time periods selected to examine per scenario.

The quantification of the risk from vehicles carrying dangerous goods, was estimated from the risk analysis for the selected route and periods. Using these data and the model QRAM, we calculated the Expected Value (EV), which expresses the number of deaths due to accidents with dangerous goods involved, given that there are no restrictions on their transport. These values derived as output of the analysis that uses the model QRAM (Table 9).

Also, the Expected Value was calculated for the most important hazards that 


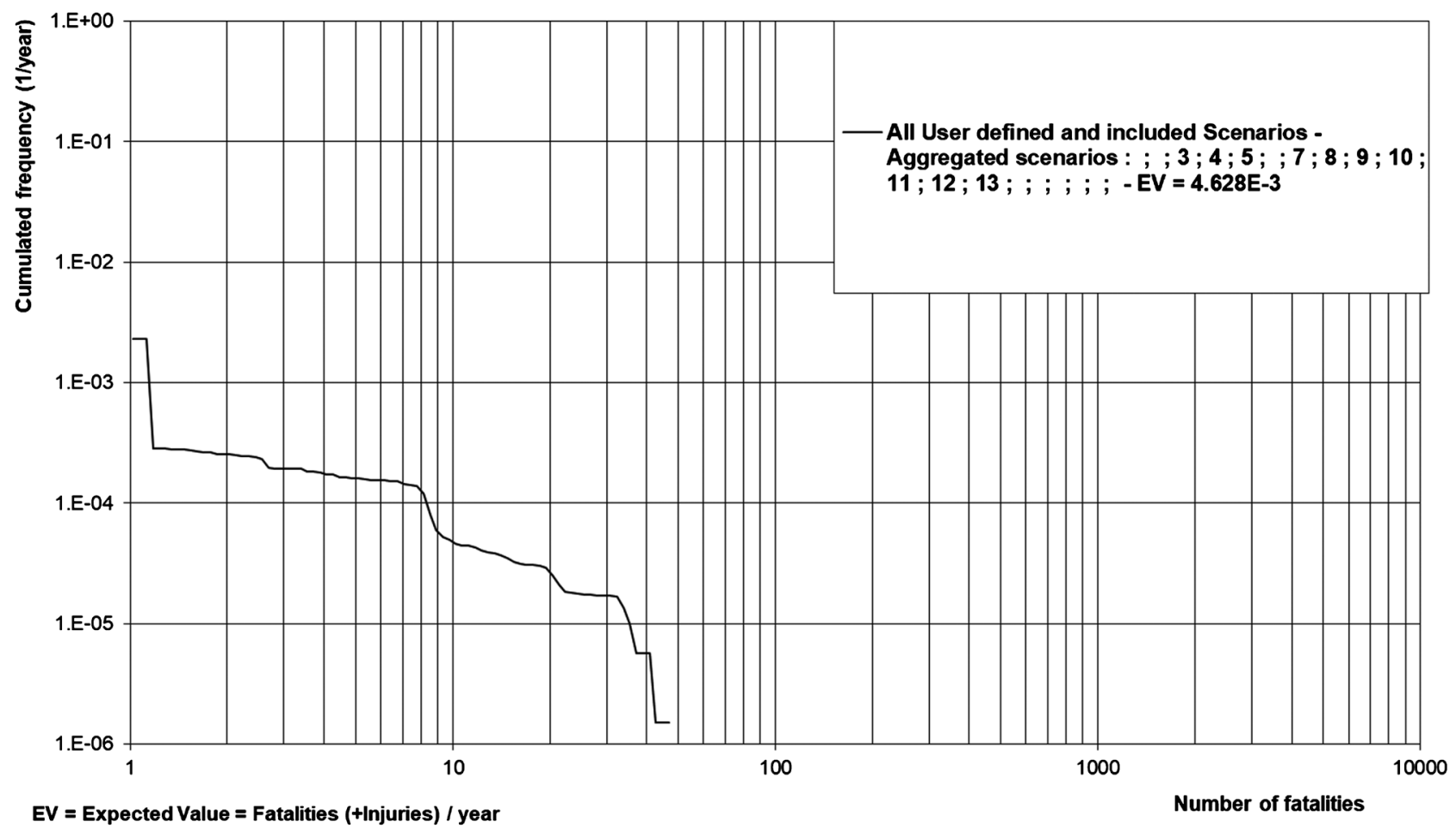

Figure 5. Societal Risk when DG-HGV passing through B6 National road - F/N Curve - Time period August/Day/Weekdays.

Table 9. Expected Value per time period when vehicles passing through the Alternative route.

\begin{tabular}{cc}
\hline Time Period & Calculated Expected Value \\
\hline Period 1 & $4.628 \mathrm{E}-03$ \\
Period 2 & $8.631 \mathrm{E}-03$ \\
Period 3 & $5.368 \mathrm{E}-03$ \\
Period 4 & $9.888 \mathrm{E}-03$ \\
Period 5 & $5.476 \mathrm{E}-04$ \\
Period 6 & $8.990 \mathrm{E}-04$ \\
Period 7 & $5.910 \mathrm{E}-04$ \\
Period 8 & $9.377 \mathrm{E}-04$ \\
\hline
\end{tabular}

might occur during the transportation of dangerous goods. The following table summarizes the annual expected fatalities from the consequences of an accident due to the involvement of the carried dangerous goods examined (Expected Value) per time period in case vehicles are passing through the Alternative route.

The resulted values presented in Table 9 calculate the annual expected fatalities from the consequences of an accident due to accidents with the involvement of heavy goods vehicle carrying dangerous goods. It is observed that Scenarios examined Period 1 to Period 4 present the higher values. These periods stand for August which is the most tourist month of the year. Interpretating the values de- 
rived only for the alternative route of Periods 1 to 4 , August pose higher risks for the public and the personnel involved in the transportation, therefore, the optimum routing for the transportation of dangerous goods should be allowed only from the basic route.

\section{Expected value with annual data}

A risk analysis conducted taking into account only annual statistical data from the relevant organisations. These data were processed in order to calculate the risk for a whole year for both routes. The preliminary risk assessment with Annual Data conducted using the quantitative risk assessment model of the Organization for Economic Cooperation and Development (OECD) and the International Association of Road (PIARC). The results of the Risk Analysis have been obtained in the form of cumulative F-N curves illustrating the calculated Expected Value (Figure 6).

In this case only one scenario examined based to Annual data for both routes. All the necessary data described in detail at the previous chapter were evaluated and finally inserted at the QRAM in order to calculate the cumulative F-N curves. The required input data for risk assessment entered at the software at a specific formulation in order the calculation and the results to be valid and accurate. QRAM input data concerned Route Description, Tunnel Description, Period of interest, Information on Local Population, Meteorological conditions, Traffic data, percentage of DG-HGV Traffic, Traffic accident.

In this analysis there are no certain time periods examined which might affect

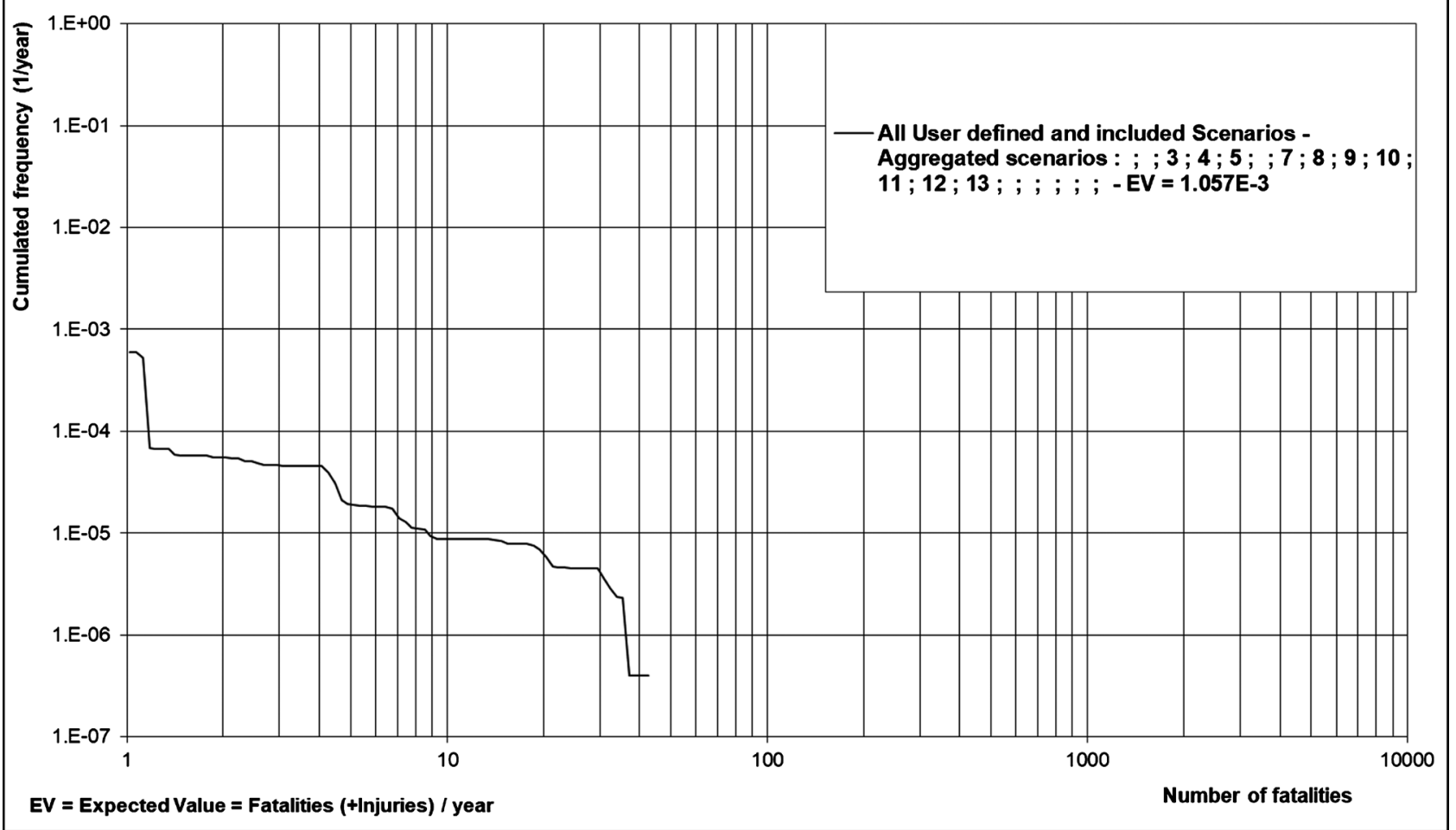

Figure 6. Societal Risk when DG-HGV passing through B6 National road-F/N Curve-Annual statistical data. 
the final outcome of the analysis. Routing decisions concerning DG-HGV that might be affected from travelling risk source, transportation network or impact area aren't available and the conclusions that derive from that kind of analysis might lead to misleading decisions with consequences to public safety.

The quantification of the risk from vehicles carrying dangerous goods, was estimated from the risk analysis for the selected routes. Using these data and the model QRAM, we calculated the Expected Value (EV), which expresses the number of deaths due to accidents in the tunnel with dangerous goods involved, given that there are no restrictions on their transport. These values derived as output of the analysis that uses the model QRAM. The following table summarizes the calculated Expected Values with Annual Data for both routes.

The resulted values presented in Table 10 calculate the annual expected fatalities from the consequences of an accident due to accidents with the involvement of heavy goods vehicle carrying dangerous goods based to annual data. Based to these data the optimum routing for the transportation of dangerous goods which offers higher level of safety to the society and the personnel involved in the transportation passes through the Alternative route. The calculated Expected Value for the annual number of expected fatalities from the consequences of an accident due to the involvement of the carried dangerous goods for the Basic route is $3.425 \times 10^{-3}$ fatalities/year, compared with $1.057 \times 10^{-3}$ fatalities/year when passing through the Alternative route.

\section{Conclusions}

The quantification of the risk from vehicles carrying dangerous goods, was estimated from the risk analysis for the selected routes and periods, it is conducted with the use of the QRAM software. The overall assessment of the risk of the Basic route, expressed through the expected value (EV) has been presented at Table 8. An additional analysis and study of the risk of the alternative route that bypasses the Basic route and the tunnel and uses the National road network, it was conducted also expressed with the expected value (EV) that has been presented at Table 9. And finally, risk analysis based to annual statistical data was conducted for both routes and the calculated expected value (EV) has been presented at Table 10.

The Expected Values that were calculated with the real time "simulation" data and with the annual statistical data for both routes and for scenarios $1,2,3,4,5,7$, $8,9,10,11,12$ and 13 of the QRAM software are presented at the following table.

These values show the annual number of expected fatalities from the consequences of an accident due to the involvement of the carried dangerous goods

Table 10. Calculated expected value using annual data.

\begin{tabular}{ccc}
\hline \multirow{2}{*}{ Time Period } & \multicolumn{2}{c}{ Calculated Expected Value } \\
\cline { 2 - 3 } & Basic Route & Alternative Route \\
\hline Annual Data & $3.425 \mathrm{E}-03$ & $1.057 \mathrm{E}-03$ \\
\hline
\end{tabular}


Table 11. Comparison of the calculated expected values per time period for both routes.

\begin{tabular}{cccc}
\hline \multirow{2}{*}{ Examined Cases } & Time Period & \multicolumn{2}{c}{ Calculated Expected Values (EV's) } \\
\cline { 3 - 4 } & & Basic Route & Alternative Route \\
\hline Case 1 & Period 1 & $4.355 \mathrm{E}-03$ & $4.628 \mathrm{E}-03$ \\
Case 2 & Period 2 & $8.051 \mathrm{E}-03$ & $8.631 \mathrm{E}-03$ \\
Case 3 & Period 3 & $3.182 \mathrm{E}-03$ & $5.368 \mathrm{E}-03$ \\
Case 4 & Period 4 & $5.875 \mathrm{E}-03$ & $9.888 \mathrm{E}-03$ \\
Case 5 & Period 5 & $2.713 \mathrm{E}-03$ & $5.476 \mathrm{E}-04$ \\
Case 6 & Period 6 & $3.935 \mathrm{E}-03$ & $8.990 \mathrm{E}-04$ \\
Case 7 & Period 7 & $2.232 \mathrm{E}-03$ & $5.910 \mathrm{E}-04$ \\
Case 8 & Period 8 & $3.560 \mathrm{E}-03$ & $9.377 \mathrm{E}-04$ \\
Case 9 & Period 9 & $3.425 \mathrm{E}-03$ & $1.057 \mathrm{E}-03$ \\
\hline
\end{tabular}

per time period and for both routes [6].

Based on the results presented in Table 11 concerning the examined cases (Case 1 to 8 ) resulting from a risk analysis using "simulated" real time data specific time periods may be pose higher risks for the public and the personnel involved in the transportation, therefore, transportation of dangerous goods from that routes should not be allowed. According to the risk estimation concluded the risk analysis, in August, which is the examined cases (Case 1 to 4), vehicles carrying dangerous goods is safer to use the Basic route than passing through the Alternative route. The calculated expected values show that the annual number of expected fatalities from the consequences of an accident due to the involvement of the carried dangerous goods is lower to the Basic route compared with these of the Alternative route. Vice versa is the case for all the other months of the year. Values calculated for the examined cases, Cases 5 to 8 , which are also based on "simulated" real time data, show that is safer for vehicles carrying dangerous goods to use the alternative route (National road network) than passing through the tunnel and the Basic route.

According to the resulted values of the examined Case 9 which is based to annual statistical data, the route offers higher level of safety to the society and the personnel involved in the transportation passes through the Alternative route. The calculated Expected Value for the annual number of expected fatalities from the consequences of an accident due to the involvement of the carried dangerous goods for the Basic route is $3.425 \times 10^{-3}$ fatalities/year, compared with $1.057 \times 10^{-3}$ fatalities/year when passing through the Alternative route. Keeping in mind these values risk analysis may conclude to misleading decisions with consequences to public safety.

Evaluating the estimated risk for the examined cases using "simulated" real time data it is consider safer for vehicles carrying dangerous goods to use the Alternative route for both directions for the eleven (11) months of the year but not at August. During August that route poses higher risks for the public and the 
personnel involved in the transportation so the route passing through the tunnel and the Basic route is safer. This isn't the case for the examined case using annual statistical data which considers as safer the route passing through the Alternative route for all the time of a year.

The root cause of the conflicting results is the elaboration of different data input sets. Annual statistical data lack in detail compared with the "simulated" real time data examined. Annual data incorporate certain variations of critical factors that must be assessed in real time in order to have an effect on the final outcome. Seasonality at a touristic area has a serious impact at critical parameters considered at the risk assessment, such as the population density, the accident rate, the monthly average daily traffic etc.. The variation of these parameters is critical for the computations of the risk analysis and may be vanished when annual statistical data must be evaluated.

As a conclusion, risk analysis conducted for dangerous good transportation clearly states that values resulted based on "simulated" real time data (traffic flows, meteorological conditions, population density etc.) acquisition compared with those concluded from statistical annual data for the above-mentioned factors specify with accuracy the periods for the selected routes which can offer higher level of safety to the society and the personnel involved in the transportation.

The results of the present study should act as springboard for further investigation and improvement of the dangerous goods transportation in order to enhance safety making the DG Risk transportation totally digitalized as a risk management process with real time data acquisition and real time risk assessment through an online GPS platform.

\section{Acknowledgements}

Authors gratefully acknowledge the support received from the Research Promotion Foundation of Cyprus in order to develop the DG Tool project in the context of the program for research, technological development and innovation "Research Restart 2016-2020".

\section{Conflicts of Interest}

The authors declare no conflicts of interest regarding the publication of this paper.

\section{References}

[1] Toumazis, I. and Kwon, C. (2013) Routing Hazardous Materials on Time-Dependent Networks Using Conditional Value-at-Risk. Transportation Research Part C: Emerging Technologies, 37, 73-92. https://doi.org/10.1016/j.trc.2013.09.006

[2] Chakrabarti, U.K. and Parikh, J.K., (2013) A Societal Risk Study for Transportation of Class-3 Hazmats-A Case of Indian State Highways. Process Safety and Environmental Protection, 91, 275-284. https://doi.org/10.1016/j.psep.2012.06.009

[3] Cappanera, P. and Nonato, M., (2014) The Gateway Location Problem: A Cost Oriented Analysis of a New Risk Mitigation Strategy in Hazmat Transportation. 
Procedia-Social and Behavioral Sciences, 111, 918-926.

https://doi.org/10.1016/j.sbspro.2014.01.126

[4] Mahmoudabadi, A. and Seyedhosseini, S.M. (2013) Developing a Chaotic Pattern of Dynamic Hazmat Routing Problem. IATSS Research, 37, 110-118.

https://doi.org/10.1016/j.iatssr.2013.06.003

[5] ADR (2019) United Nations Economic Commission for Europe. https://unece.org/adr-2019-files

[6] OECD (2001) Transport of Dangerous Goods through Road Tunnels. Research Report, January 2001.

https://www.itf-oecd.org/safety-tunnels-transport-dangerous-goods-through-road-t unnels

[7] Vagiokas, N. (2018) Fire Hazards of Transportation of Fuels. The International Journal of Engineering and Science (IJES), 7, 38-48.

[8] Hall, R., Knoflacher, H. and Pons, P. (2006) Quantitative Risk Assessment Model for Dangerous Goods Transport through Road Tunnels. Piarc Internet, RoutesRoads 2006, No. 329. https://www.piarc.org/ressources/publications/3/5089,RR329-UK.pdf

[9] https://en.wikipedia.org/wiki/A6 motorway (Cyprus)

[10] Vagiokas, N. (2018) Developing a Methodology for Determining Design and Operating Requirements for Contracting Tunnel Works. Open Access Library Journal, 5, Article ID: e4741. https://doi.org/10.4236/oalib.1104741

[11] Lees, F.P. (1996) Loss Prevention in the Process Industries. 2nd Edition, Butterworth-Heinemann, Oxford.

[12] 14th Census of Population in Cyprus (2011) Statistical Service of Cyprus. https://www.mof.gov.cy/mof/cystat/statistics.nsf/census-2011 cystat en/census-201 1 cystat en

[13] Statistical Data (2016) Cyprus Police. https://www.police.gov.cy/police/police.nsf/dmlstatistical en/dmlstatistical en?Ope $\underline{\text { nDocument }}$ 